\title{
Effect of oxidation of catalytically active silicon-based electrodes on water decomposition
}

\author{
V.E. Primachenko, O.A. Serba, V.A. Chernobai, E.F. Venger \\ V. Lashkaryov Institute of Semiconductor Physics, NAS of Ukraine \\ 41, prospect Nauky, 03028 Kyiv, Ukraine \\ E-mail:pve18@isp.kiev.ua
}

\begin{abstract}
In this work, we continue to study the revealed phenomenon of current creation in the electrochemical system with distilled water during its decomposition without any applied external voltage. Investigated are catalytically active (to decompose water) electrodes based on silicon with modified surface (due to lapping, texturing, doping with palladium, creation of silicides) before and after thermooxidizing for 1 hour in dry oxygen at $850{ }^{\circ} \mathrm{C}$. Also performed are investigations of time dependences for the current between silicon electrodes and counter-electrodes made of $\mathrm{Al}, \mathrm{Pt}, \mathrm{Yb}$ when using the circuit with the external voltage $V_{0}= \pm 9.7 \mathrm{~V}$. Analyzed are the results obtained and prospects for a further study.
\end{abstract}

Keywords: current creation, external voltage, water decomposition, catalytically active electrodes, oxidation.

Manuscript received 20.11.06; accepted for publication 26.03.07; published online 01.06.07.

\section{Introduction}

In the works [1, 2], we realized decomposition of water by hydrogen and oxygen by using various catalytically active (as to this decomposition) electrodes inside distilled water without applying any external voltage to them. This decomposition is realized due to the reaction $\mathrm{H}_{2} \mathrm{O} \rightarrow \mathrm{HO}^{-}+\mathrm{H}^{+}$taking place on one or both catalytically active electrodes (cathode and anode) with the following separation of anions $\left(\mathrm{OH}^{-}\right)$and cations $\left(\mathrm{H}^{+}\right)$ by the electric voltage arising due to different electrochemical potentials (electron work functions) for these two materials used as anode and cathode.

This electrochemical system operates as a current source (unfortunately, with a low power of the order of $0.025 \mathrm{~mW} / \mathrm{cm}^{2}$, up to date). In so doing, in dependence on electrode material one can observe both a decrease and increase (up to $50 \%$ ) of the current value with time (experiments were carried out for $30 \ldots 180 \mathrm{~min}$ ) [1,2]. Besides, in future one shall be able to use hydrogen that is released from the cathode or accumulated in it.

Our analysis of the experimental conditions showed that obtaining the energy (in the form of the current source and hydrogen) is realized due to a natural difference of electrochemical potentials between different materials used as electrodes as well as due to electrochemical reactions with liberation of $\mathrm{OH}^{-}$and $\mathrm{H}^{+}$ ions at these electrodes, which promotes keeping the potential difference between the electrodes within some limits. In principle, there is a possibility to absorb some amount of the heat energy of the electrochemical system medium. At the same time, some reference experiments showed that possible photochemical processes related to absorption of sun light quanta do not play any essential role in our conditions.

As it follows from $[1,2]$, the efficiency of energy output in these electrochemical systems depends on many factors, in particular, on the degree of oxidation of the electrodes in use. For instance, the Yb-Pt system operates more effectively under some definite degree of oxidation inherent to the $\mathrm{Yb}$ electrode, although the potential difference between $\mathrm{Yb}$ and $\mathrm{Pt}$ electrodes is decreased. It is related with the higher catalytic activity of the $\mathrm{Yb}$ electrode, when an inhomogeneous oxide film with the composition of the $\mathrm{Yb}_{2} \mathrm{O}_{3}$ type is created on it. The high catalytic activity of metal oxides in reduction reactions, to which the water decomposition can be related, is well known [3].

In this work, we performed investigations of the efficiency of energy generation by using the above electrochemical water system with modified silicon and its compounds obtained after oxidizing them.

\section{Experimental}

In this work, as an anode we used electrodes made of $\mathrm{Yb}$ or Al that possess a lower electron work function as compared with silicon or its compounds (cathodes). On 
the other hand, as it was revealed in investigations, silicon electrodes can play the role both of the anode and cathode relative to the comparatively stable Pt electrode. Therefore, we performed vast investigations of the efficiency of energy generation by using the above water system with $\mathrm{Al}, \mathrm{Pt}, \mathrm{Yb}$ electrodes in combination with silicon electrodes, the state of which was changed (lapping, texturing, doping with $\mathrm{Pd}$, oxidation, creation of silicides $\mathrm{Cr}_{3} \mathrm{Si}, \mathrm{Ni}_{3} \mathrm{Si}$ ).

When carrying out the experiments, the couple of corresponding electrodes mounted on the same holder was dipped into distilled water. The space between electrodes was within limits $L=1 \ldots 2 \mathrm{~cm}$, their area $S$ was between 0.5 to $2 \mathrm{~cm}^{2}$. After $1 \ldots 2 \mathrm{~min}$ from the moment of dipping the electrodes, using an electron voltmeter we measured the voltage $\Delta V_{c}$ between electrodes, and then, after connection with the external electric circuit, using a microamperemeter we measured time dependences for the current provided by the movement of $\mathrm{OH}^{-}$and $\mathrm{H}^{+}$ions in water.

As in the case of various couples of electrodes, the values $L, S, \Delta V_{c}$ were different, to compare the effect of electrodes on the rate of water decomposition, we plotted the time dependences for the specific conductivity of the electrochemical system:

$\sigma_{\text {eff }}=J(t)\left(L / \Delta V_{c} \cdot S\right)=A J(t)$,

where the coefficient $A=L /\left(\Delta V_{c} \cdot S\right) \mathrm{V}^{-1} \mathrm{~cm}^{-1}$. In addition to measurements of the current $J(t)$ caused by the difference $\Delta V_{c}$, we also measured the currents when the external circuit was added by an additive power source with $V_{0}=9.7 \mathrm{~V}$ (battery) and the respective sign "+" or "-_" on the silicon electrode. It enables us to make some conclusions about the role of the potential difference between the electrodes in the value of the conductivity $A J(t)$ for this electrochemical system. In these cases, in the formula (1) we used the value $\pm V_{0}+\Delta V_{c}$.

As a rule, $\mathrm{Al}, \mathrm{Pt}$ and $\mathrm{Yb}$ electrodes were plain metal plates. Silicon electrodes, in most cases, were plain plates made of $n$-type silicon ( $2 \mathrm{Ohm} \cdot \mathrm{cm},(100)$ face), but their surface was modified. Namely, we used: silicon surfaces grinded with diamond paste (grain diameter of which was close to $1 \mu \mathrm{m}$ ); surfaces preliminary textured with the etchant [4], when tetrahonal pyramids of approximately $2-\mu \mathrm{m}$ height with side faces (111) were created on them; grinded or textured surfaces doped with Pd by using water solutions of $\mathrm{PdCl}_{2}\left(10^{-3}-10^{-2} \mathrm{M}\right)$; surfaces of specially grown silicides $\left(\mathrm{Cr}_{3} \mathrm{Si}, \mathrm{Ni}_{3} \mathrm{Si}\right)$; all the abovementioned surfaces after thermal oxidizing them at $850{ }^{\circ} \mathrm{C}$ for 1 hour in dry $\mathrm{O}_{2}$. Work functions for electron escaping from electrodes $\varphi$ were measured by us directly in experiments relative to $\mathrm{Pt}$ electrode, the work function of which is well known $\left(\varphi_{\mathrm{Pt}}=5.32 \mathrm{eV}[5]\right)$. We took into account that $\mathrm{Pt}$ is the most chemically stable material, therefore, it possesses the relatively stable value of the work function as compared with other materials. To determine $\varphi$-value for other electrodes, we applied the voltage $\left(V_{0}=9.7 \mathrm{~V}\right)$ between them and Pt electrode first in one and then in the opposite direction.

Currents $J_{1}$ and $J_{2}$ were measured with a microamperemeter after their fast (less than $5 \mathrm{~s}$ ) stabilization in the electric circuit, when equilibrium of the electron subsystem had been already reached, while that for the ionic subsystem will be reached considerably later, which will cause an essential change of electrode polarization due to chemical reactions on them. Using the following equations:

$J_{1}=\left(V_{0}-\Delta \varphi / q\right) / R$

and

$J_{2}=\left(V_{0}+\Delta \varphi / q\right) / R$,

where $\Delta \varphi$ is the difference of electron work functions between the electrodes, $q$ is the electron charge and $R$ is the resistance of the electrochemical system, we determined the value:

$\Delta \varphi / q=V\left(J_{2}-J_{1}\right) /\left(J_{2}+J_{1}\right)$,

and then the values $\varphi_{\mathrm{el}}$ for the investigated electrode

$\varphi_{\mathrm{el}}=(5.32-\Delta \varphi) \mathrm{eV}$.

It is noteworthy that the values $\varphi_{\mathrm{el}}$ obtained in this manner, for instance, for $\mathrm{Al}$ and $\mathrm{Ni}$ electrodes were in good agreement with their values determined by other methods $[5,6]$.

\section{Experimental results and discussion}

It is known that under the room temperature water contains ions $\mathrm{OH}^{-}$and $\mathrm{H}^{+}$in concentrations $1.2 \cdot 10^{14} \mathrm{~cm}^{-3}, \mathrm{H}^{+}$ions being in complexes $\mathrm{H}_{5} \mathrm{O}_{2}{ }^{+}$[6]. After dipping the electrode into water, there arises electron-ion exchange between them, which causes a potential hop (the so-called Galvani-potential [7]). The latter comprises at least the following components: a potential drop in a diffusion (for ions) water layer near the electrode; potential drop in the thin $\left(\sim 10^{-8} \mathrm{~cm}\right)$ Helmholtz layer created by ions close to electrode surface; potential drop in the very electrode (it is essential for electrodes made of semiconductors that have a subsurface space charge layer [8]). Besides, when the thickness and resistance of the oxide layer covering the electrode are considerable, an essential part of the Galvani-potential can drop in this layer.

If a pair of chosen electrodes is dipped into water simultaneously, there arises electron-ion equilibrium with a respective potential difference $\Delta V_{c}$. It is realized due to different values of their electrochemical potentials (by another words, owing to different electron work functions $\varphi$ of these electrodes). One can observe a partial transition of electrons from the electrode with a higher electrochemical potential (and a lower $\varphi$-value) to the electrode with a lower electrochemical potential (and a higher $\varphi$-value). As a result, the former electrode 
becomes positively charged (i.e., becomes anode), while the latter - negatively charged (i.e., becomes cathode). It is noteworthy that, in accord with experimental data, the initial potential difference between the electrodes $\Delta V_{\mathrm{c}}$ before current going between them was always lower than the difference $\Delta \varphi / q$ for electrodes. Then, if one makes an external electric circuit to close, there arises a current, electrons being in movement from anode to cathode, as in water $\mathrm{OH}^{-}$ions move to anode, while $\mathrm{H}^{+}$ $\left(\mathrm{H}_{5} \mathrm{O}_{2}^{+}\right)$ions do to cathode.

In the course of water decomposition when $\mathrm{OH}^{-}$ ions discharge on the anode and $\mathrm{H}^{+}$ions on the cathode, the $\Delta V_{\mathrm{c}}$ value, in principle, should decrease and vanish with time. But it did not observe in the variety of used electrodes, in the first place, owing to electrochemical reactions on the electrodes.

In accordance with $[3,9]$, electrolysis of water (with $\mathrm{pH} \approx 7$ ) on the anode can be described by the following reactions:

$4 \mathrm{OH}^{-}=\mathrm{O}_{2}+2 \mathrm{H}_{2} \mathrm{O}+4 \mathrm{q}^{-}$

$2 \mathrm{H}_{2} \mathrm{O}=\mathrm{O}_{2}+4 \mathrm{H}^{+}+4 \mathrm{q}^{-}$

as well as on the cathode:

$2 \mathrm{H}_{5} \mathrm{O}_{2}^{+}+2 \mathrm{q}^{-}=\mathrm{H}_{2}+4 \mathrm{H}_{2} \mathrm{O}$

$2 \mathrm{H}_{2} \mathrm{O}+2 \mathrm{q}^{-}=\mathrm{H}_{2}+2 \mathrm{OH}^{-}$.

However, the above reactions do not take into account a possible catalytic action of electrodes, reactions of bond creation of oxygen and hydrogen with electrode matter (including diffusion into them), mechanisms of oxygen and hydrogen desorption from electrodes. As it was shown for example in $[1,2]$, in the pair $\mathrm{Yb}$-Pt catalytic phenomena of water decomposition on the $\mathrm{Yb}$ electrode play an essential role, while in the case of a plain Pt electrode, chemically stable, covered with a super-thin oxide layer, these phenomena can be ignored in the first approximation.

It was noted in Introduction that the main purpose of this work is to study the role of oxidation of electrodes based on silicon in the process of current creation when water is decomposed in electrochemical systems. First, we shall consider these phenomena for the case of thermal oxidation of polished and textured silicon electrodes, then after oxidation of these electrodes preliminary doped with $\mathrm{Pd}$, and in fine after oxidation of metal silicides $\left(\mathrm{Cr}_{3} \mathrm{Si}\right.$ and $\left.\mathrm{Ni}_{3} \mathrm{Si}\right)$.

I. Time dependences $A J(t)$ for the current through silicon electrodes were measured using plates of $\mathrm{Pt}, \mathrm{Yb}$, $\mathrm{Al}$ as counter-electrodes. The results for the Pt electrode are shown in Figs 1 and 2 as $A J(t)$ dependences for polished and textured silicon surfaces, respectively, before (curves $1,1^{(+)}, 1^{(-)}$) and after (curves $2,2^{(+)}, 2^{(-)}$) their thermal oxidation for 1 hour at $T=850{ }^{\circ} \mathrm{C}$ in dry $\mathrm{O}_{2}$. The thickness of the $\mathrm{SiO}_{2}$ oxide film on silicon reaches up to $40 \mathrm{~nm}$ in this regime of growing. The curves 1 and 2 were obtained when external voltage was $V_{0}=0$, curves marked with the sign $(+)$ correspond to $V_{0}=+9.7 \mathrm{~V}$ on silicon electrodes, while with the sign (-) to $V_{0}=-9.7 \mathrm{~V}$.

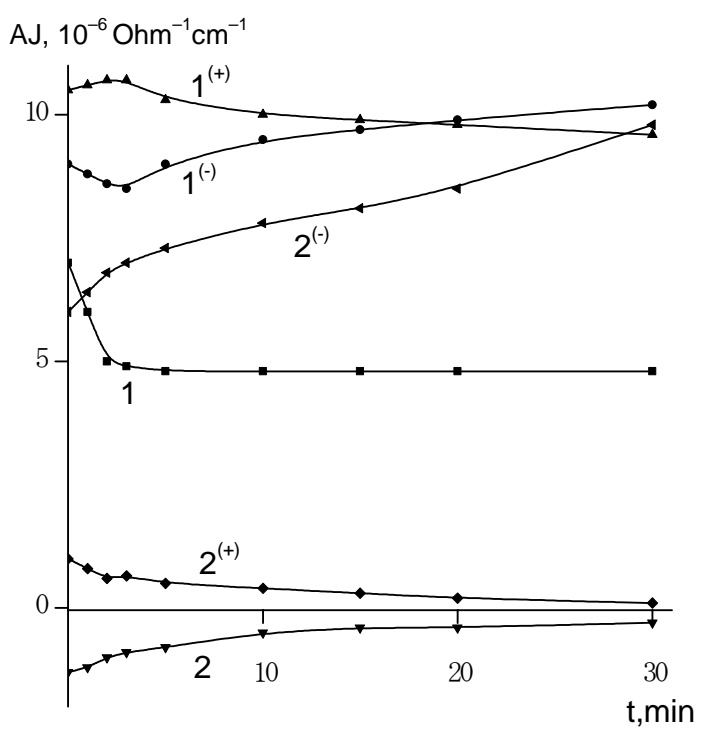

Fig. 1. Time dependences of the effective conductivity $A J(t)$ obtained for the electrochemical water system with the pair of electrodes $\mathrm{Pt}_{-} \mathrm{Si}^{\mathrm{p}}\left(1,1^{(+)}, 1^{(-)}\right.$- before and $2,2^{(+)}, 2^{(-)}-$after thermal oxidation of $\mathrm{Si}^{\mathrm{p}} ; 1,2-V_{0}=0 ;(+)-V_{0}=+9.7 \mathrm{~V}$ on $\mathrm{Si}^{\mathrm{p}} ;(-)-V_{0}=-9.7 \mathrm{~V}$ on $\left.\mathrm{Si}^{\mathrm{p}}\right)$.

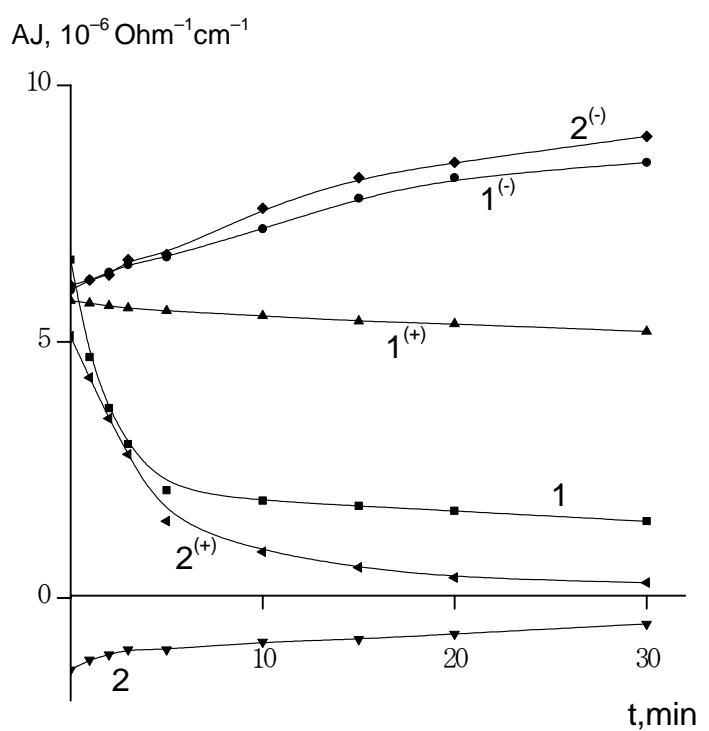

Fig. 2. Time dependences of $A J(t)$ for the electrode pair Pt-Si ${ }^{\mathrm{t}}$ $\left(1,1^{(+)}, 1^{(-)}-\right.$before and $2,2^{(+)}, 2^{(-)}-$after thermal oxidation of $\mathrm{Si}^{\mathrm{t}} ; 1,2-V_{0}=0 ;(+)-V_{0}=+9.7 \mathrm{~V},(-)-V_{0}=-9.7 \mathrm{~V}$ on $\left.\mathrm{Si}^{\mathrm{t}}\right)$.

First of all, let us analyze the $A J(t)$ dependence when $V_{0}=0$ before oxidation of silicon electrodes (curves 1). For both polished $\mathrm{Si}^{\mathrm{p}}$ and textured $\mathrm{Si}^{\mathrm{t}}$ electrodes, initial values of the efficient conductivity are practically the same at $t=0$. Then, one can see a relatively fast drop of $A J(t)$ (in the case of $\mathrm{Si}^{\mathrm{p}}$ for $2 \mathrm{~min}$, and $\mathrm{Si}^{\mathrm{t}}$ for $5 \mathrm{~min}$ ), which can be associated with separation of $\mathrm{H}^{+} \mathrm{i} \mathrm{OH}^{-}$ions that were created near the electrodes before $t=0$ due to catalytic action of the latter 
on water decomposition. For the times $t \geq 5 \mathrm{~min}, A J(t)$ values for the $\mathrm{Si}^{\mathrm{p}}$ electrode are quasi-stationary, while for $\mathrm{Si}^{\mathrm{t}}$ electrode these are decreased to some extent, being more than 2 times less as compared with those for $\mathrm{Si}^{\mathrm{p}}$ electrode. Some clarity in understanding the $A J(t)$ dependences for $\mathrm{Si}^{\mathrm{p}}$ and $\mathrm{Si}^{\mathrm{t}}$ can be reached using measurements of $\Delta V_{\mathrm{c}}$ before the current starts (at $t=0$ ) and after its switching off $(t \geq 30 \mathrm{~min})$, i.e., $\Delta V_{\mathrm{c}}^{(1)}$ and $\Delta V_{\mathrm{c}}^{(2)}$, respectively. In the case of $\mathrm{Si}^{\mathrm{p}}$ electrode, these values were $\Delta V_{\mathrm{c}}^{(1)}=+0.50 \mathrm{~V}$ and $\Delta V_{\mathrm{c}}^{(2)}=+0.44 \mathrm{~V}$, while for $\mathrm{Si}^{\mathrm{t}}$ electrode, $\Delta V_{\mathrm{c}}^{(1)}=+0.38 \mathrm{~V}$ and $\Delta V_{\mathrm{c}}^{(2)}=+0.18 \mathrm{~V}$. The higher values of $V_{\mathrm{c}}^{(1)}$ and $\Delta V_{\mathrm{c}}^{(2)}$ for $\mathrm{Si}^{\mathrm{p}}$ electrode define the distinction between $A J(t)$ dependences for $\mathrm{Si}^{\mathrm{p}}$ and $\mathrm{Si}^{\mathrm{t}}$ electrodes as a consequence of stronger local electric fields arising near non-homogeneities of the polished surface, which enhances its catalytic activity in water decomposition. This conclusion is confirmed by $A J(t)$ dependences obtained for $\mathrm{Si}^{\mathrm{p}}$ and $\mathrm{Si}^{\mathrm{t}}$ electrodes when applying the voltage $V_{0}= \pm 9.7 \mathrm{~V}$ to them (curves $1^{(+)}$and $1^{(-)}$in Figs 1 and 2 ). The considerably higher $A J(t)$ values for these curves (at $t \geq 5 \mathrm{~min}$ ) as compared with the curves 1 are unambiguously indicative of the fact that the efficient conductivity $A J(t)$ of these electrochemical systems essentially grows with increasing the voltage between electrodes, which results in a higher catalytic activity of the electrodes in water decomposition.

Determined work functions for electrons before thermal treatments of electrodes for $\mathrm{Si}^{\mathrm{p}}$ and $\mathrm{Si}^{\mathrm{t}}$ were $\varphi_{\mathrm{p}}=$ $=4.47 \mathrm{eV}$ and $\varphi_{\mathrm{t}}=4.85 \mathrm{eV}$, respectively. In our opinion, the difference between $\varphi_{\mathrm{p}}$ and $\varphi_{\mathrm{t}}$ is caused by the higher density of surface electron states (SES) on the polished surface as compared to the textured one, which provides a larger electron charge in SES that bends the energy bands down and results in lowered $\varphi_{\mathrm{p}}$ as compared with $\varphi_{t}$. However, both electrodes behave as anodes relatively to the Pt electrode.

Quite another situation is realized after thermal treatments (TT) of $\mathrm{Si}^{\mathrm{p}}$ and $\mathrm{Si}^{\mathrm{t}}$ electrodes. In the case of $\mathrm{Si}_{\mathrm{TT}}{ }^{\mathrm{p}}$ electrode, we found $\varphi_{\mathrm{TT}}^{\mathrm{p}}=10.5 \mathrm{eV}$, but for $\mathrm{Si}_{\mathrm{TT}}{ }^{\mathrm{t}}$ $\varphi_{\mathrm{TT}}{ }^{\mathrm{t}}=11.4 \mathrm{eV}$, that is relatively to Pt electrode $\left(\varphi_{\mathrm{Pt}}=\right.$ $5.32 \mathrm{eV})$ thermally treated silicon electrodes behave as cathodes. High $\varphi$-values in this case are indicative of the fact that we measure the work function not for silicon but for an oxide film $\mathrm{SiO}_{2}$ that covers silicon. It is known [10] that the width of the $\mathrm{SiO}_{2}$ forbidden gap is equal to $\Delta E_{\mathrm{g}}=9 \mathrm{eV}$, while the energy of electron affinity $\chi=0.9 \mathrm{eV}$, i.e., the energy distance from the top of filled with electrons $\mathrm{SiO}_{2}$ valence band to the vacuum level is $\Delta E_{g}+\chi=9.9 \mathrm{eV}$. It should be the value of the work function for $\mathrm{SiO}_{2}$. The values obtained by us for the thermooxidized $\mathrm{Si}^{\mathrm{p}}$ and $\mathrm{Si}^{\mathrm{t}}$ electrodes exceed that value by 0.6 and $1.5 \mathrm{eV}$, respectively. In our case, this $\varphi$ excess can be caused both by a positive charge built-in inside the oxide films and by the layer of $\mathrm{H}^{+}$ions adsorbed on the $\mathrm{SiO}_{2}$ surface (Helmholtz's layer). We prefer the second reason, as the work function measured by us depended to some extent on the conditions of its measurements (for example, before or after measuring the $A J(t)$ dependence at $\left.V_{0}=0\right)$.

Although the difference $\Delta \varphi$ between $\mathrm{Pt}$ and thermally oxidized silicon electrodes is approximately 5 to $6 \mathrm{eV}$, the measured values $\Delta V_{\mathrm{c}}$ for these pairs do not exceed tens of microvolts. These are corresponded by low currents $J(t)$ (no more than $5 \cdot 10^{-8} \mathrm{~A}$ ). It is caused by the fact that the main part of voltage drop $\Delta \varphi / q$ is related to the $\mathrm{SiO}_{2}$ layer. The curves 2 in Figs 1 and 2 obtained at $V_{0}=0$ after the thermal treatment reflect these facts. Despite the fact that the conductivity value $A J(t)$ is always positive, we presented these data as negative to emphasize the opposite directions of currents before and after the thermal treatment (curves 1 and 2, respectively). As seen from Figs. 1 and 2, after the thermal treatment the $A J(t)$ magnitudes are also lower when applying the voltage $V_{0}=+9.7 \mathrm{~V}$ to silicon electrodes, while application of the voltage $V_{0}=-9.7 \mathrm{~V}$ to the same electrodes do not change these magnitudes considerably. Thus, thermal oxidation of polished and textured surfaces when using them in the pair with $\mathrm{Pt}$ electrode does not yield positive results.

Shown in Figs 3 and 4 are the $A J(t)$ dependences for polished and textured silicon electrodes, respectively, before (curves $1,1^{(+)}, 1^{(-)}$) and after (curves 2, $2^{(+)}, 2^{(-)}$) their thermal treatment in pairs with $\mathrm{Yb}$ electrodes as well as with $\mathrm{Al}$ electrode (curves $3^{(+)}, 3^{(-)}$). In all these measurements, silicon electrodes served as cathodes. Let us note the most interesting features of these dependences. First, the thermal treatment of $\mathrm{Si}^{\mathrm{p}}$ and $\mathrm{Si}^{\mathrm{t}}$ electrodes results in a positive effect in their pairs with the $\mathrm{Yb}$ electrode, namely: the $A J(t)$ value is considerably increased at $V_{0}=0$ (curves 2) and at $V_{0}=-9.7 \mathrm{~V}$ (curves $\left.2^{(-)}\right)$as compared to those $A J(t)$ values obtained before the thermal treatment (curves 1 and $1^{(-)}$). Besides, changed is the time character of these dependences: one can observe only growth of $A J(t)$ with time. It means that the character of electrochemical processes on $\mathrm{Si}^{\mathrm{p}}$ and $\mathrm{Si}^{\mathrm{t}}$ electrodes covered with $\mathrm{SiO}_{2}$ is changed after the thermal treatment, and, as a result, liberation of hydrogen on these electrodes is improved. The increase of $A J(t)$ values with time (curves 2) is caused by growing $\Delta V_{c}$ value that changed on $\mathrm{Si}^{\mathrm{p}}$ electrode within the range +0.30 up to $+0.50 \mathrm{~V}$, and on $\mathrm{Si}^{\mathrm{t}}$ electrode from +0.22 up to $+0.47 \mathrm{~V}$ (while before the thermal treatment $\Delta V_{c}$ value on $\mathrm{Si}^{\mathrm{p}}$ electrode was changed from +0.50 down to $+0.40 \mathrm{~V}$, and on $\mathrm{Si}^{\mathrm{t}}$ electrode - from +0.35 down to $+0.32 \mathrm{~V})$. Second, the pairs $\mathrm{Yb}_{-} \mathrm{Si}_{\mathrm{TT}}{ }^{\mathrm{p}}\left(\mathrm{Si}_{\mathrm{TT}}{ }^{\mathrm{t}}\right)$ are more efficient as compared with pairs where the $\mathrm{Al}$ electrode is used instead of the $\mathrm{Yb}$ one. It may be related both with a larger $\Delta \varphi$ difference in the case of $\mathrm{Yb}$ and with higher catalytic activity of $\mathrm{Yb}$. Third, after the thermal treatment of silicon electrodes when the voltage $V_{0}=+9.7 \mathrm{~V}$ is applied to them, the $A J(t)$ values (curves $\left.2^{(+)}, 3^{(+)}\right)$are considerably lower than those before the thermal treatment (curve $1^{(+)}$). It means that after oxidation the electrodes are very difficult to "take" or "create" hydrogen when their potential $V_{0}$ is positive. 


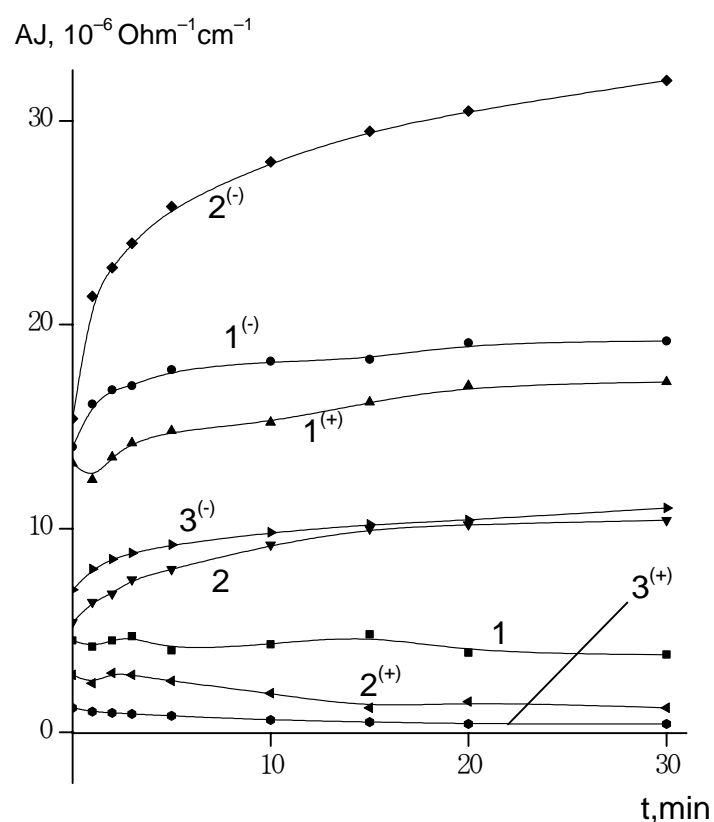

Fig. 3. $A J(t)$-dependences inherent to the electrode pairs $\mathrm{Yb}-\mathrm{Si}^{\mathrm{p}}$ $\left(1,1^{(+)}, 1^{(-)}\right.$- before; $2,2^{(+)}, 2^{(-)}$- after thermal oxidation of $\left.\mathrm{Si}^{\mathrm{p}}\right)$ and $\mathrm{Al}-\mathrm{Si}^{\mathrm{p}}\left(3^{(+)}, 3^{(-)}-\right.$after thermal oxidation of $\left.\mathrm{Si}^{\mathrm{p}}\right) ; 1,2-$ $V_{0}=0 ;(+)-V_{0}=+9.7 \mathrm{~V},(-)-V_{0}=-9.7 \mathrm{~V}$ on $\left.\mathrm{Si}^{\mathrm{p}}\right)$. The dependence $3\left(V_{0}=0\right)$ is not presented as $A J(t)$ is close to zero.

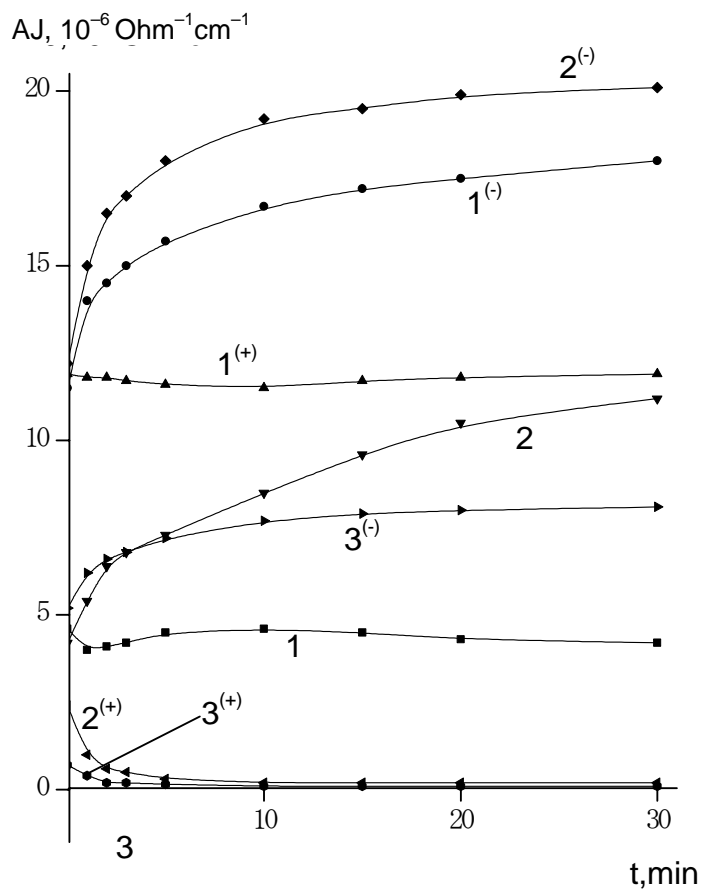

Fig. 4. $A J(t)$-dependences inherent to the electrode pairs $\mathrm{Yb}-\mathrm{Si}^{\mathrm{t}}$ $\left(1,1^{(+)}, 1^{(-)}\right.$- before; $2,2^{(+)}, 2^{(-)}$- after thermal oxidation of $\left.\mathrm{Si}^{\mathrm{t}}\right)$ and $\mathrm{Al}-\mathrm{Si}^{\mathrm{t}}\left(3^{(+)}, 3^{(-)}-\right.$after thermal oxidation of $\left.\mathrm{Si}^{\mathrm{t}}\right) .1,2-$ $V_{0}=0 ;(+)-V_{0}=+9.7 \mathrm{~V},(-)-V_{0}=-9.7 \mathrm{~V}$ on $\mathrm{Si}^{\mathrm{t}}$. The dependence $3\left(V_{0}=0\right)$ is not presented as $A J(t)$ is close to zero.
II. It was shown in our works $[1,2]$ that preliminary doping all the structurally modified silicon electrodes with Pd results in increased $A J(t)$ values, that is in an increased rate of water decomposition due to high catalytic activity of an island-like structure that is characteristic for palladium deposited on silicon from $\mathrm{PdCl}_{2}$ water solutions [8]. On the other hand, the abovementioned means that usage of the $\mathrm{Yb}$ counterelectrode increases the $A J(t)$ values like to thermal oxidation of $\mathrm{Si}^{\mathrm{p}}$ and $\mathrm{Si}^{\mathrm{t}}$ electrodes does. Therefore, it was interesting to combine the action of these two factors - doping and thermal oxidation of $\mathrm{Si}^{\mathrm{p}}$ and $\mathrm{Si}^{\mathrm{t}}$ electrodes, especially predicting that doping can considerably decrease the resistivity of $\mathrm{SiO}_{2}$ films.

Figs 5 to 8 show $A J(t)$ dependences obtained for electrodes $\mathrm{Si}^{\mathrm{p}}\left\langle\mathrm{Pd} ; 10^{-3} \mathrm{M}\right\rangle, \mathrm{Si}^{\mathrm{t}}\left\langle\mathrm{Pd} ; 10^{-2} \mathrm{M}\right\rangle, \mathrm{Si}^{\mathrm{t}}\left\langle\mathrm{Pd} ; 10^{-3} \mathrm{M}\right\rangle$ before and after their thermal treatment when these were used in pairs with $\mathrm{Pt}, \mathrm{Yb}, \mathrm{Al}$ electrodes. The notation $\left\langle\mathrm{Pd} ; 10^{-3} \mathrm{M}\right\rangle$ means that the sample of silicon is doped with palladium from $10^{-3} \mathrm{M} \mathrm{PdCl}_{2}$ water solution, the sample being kept in this solution for 1 hour.

First of all, it is worth to note that if before the thermal treatment of electrodes $\mathrm{Si}^{\mathrm{p}}\left\langle\mathrm{Pd} ; 10^{-3} \mathrm{M}\right\rangle$, $\mathrm{Si}^{\mathrm{t}}\left\langle\mathrm{Pd} ; 10^{-2} \mathrm{M}\right\rangle$ and $\mathrm{Si}^{\mathrm{t}}\left\langle\mathrm{Pd} ; 10^{-3} \mathrm{M}\right\rangle$ the electron work functions $\varphi$ determined relatively the Pt electrode were $5.24,5.12$ and $5.53 \mathrm{eV}$, respectively, then after the thermal treatment they acquired the values $4.74,4.64$ and $4.93 \mathrm{eV}$. That is, contrary to oxidation of non-doped $\mathrm{Si}^{\mathrm{p}}$ and $\mathrm{Si}^{\mathrm{t}}$ samples when $\varphi$-values were considerably grown, oxidation of Pd-doped samples causes a decrease of the electron work function, which is indicative of the low resistivity of the created $\mathrm{SiO}_{2}$ film "transfused" with palladium. It is also confirmed by $A J(t)$ dependences shown in Figs $5-8$. It is very probable that thermal treatments create palladium silicides as well as its oxides. As to that, some conclusion can be drawn from the analysis of the work function values for silicon electrodes doped with Pd. The $\varphi$-values higher than $5 \mathrm{eV}$ indicate that the island-like Pd film is oxidized, which provides the $\varphi$-values higher than that of $\operatorname{Pd}[5,6]$. Then, a decrease of $\varphi$-values after thermal treatments most likely indicates creation of palladium silicides on the electrode surface. When keeping these electrodes in air, the $\varphi$-values increase to some extent, which can be caused by oxidation of palladium silicides (oxidation in humid air can be considerably efficient than in dry $\mathrm{O}_{2}$ ).

In the beginning, we shall consider the action of silicon electrodes doped with Pd on water decomposition if these are coupled with Pt counter-electrodes (Figs. $5,6)$. The $A J(t)$ dependences obtained before and after TTs of $\mathrm{Si}^{\mathrm{p}}\left\langle\mathrm{Pd} ; 10^{-3} \mathrm{M}\right\rangle, \mathrm{Si}^{\mathrm{t}}\left\langle\mathrm{Pd} ; 10^{-2} \mathrm{M}\right\rangle$ and $\mathrm{Si}^{\mathrm{t}}\left\langle\mathrm{Pd} ; 10^{-3} \mathrm{M}\right\rangle$ electrodes essentially differ from those for electrodes $\mathrm{Si}^{\mathrm{p}}$ and $\mathrm{Si}^{\mathrm{t}}$ without Pd (Figs. 1,2). In the case of doped electrodes, $A J(t)$ values are noticeably higher both at $V_{0}=0$ and $\pm 9.7 \mathrm{~V}$, because the nondoped electrodes have $\mathrm{SiO}_{2}$ isolated layer. There is no such a layer on electrodes doped with Pd after the thermal treatment, therefore one can observe considerably higher $A J(t)$ 


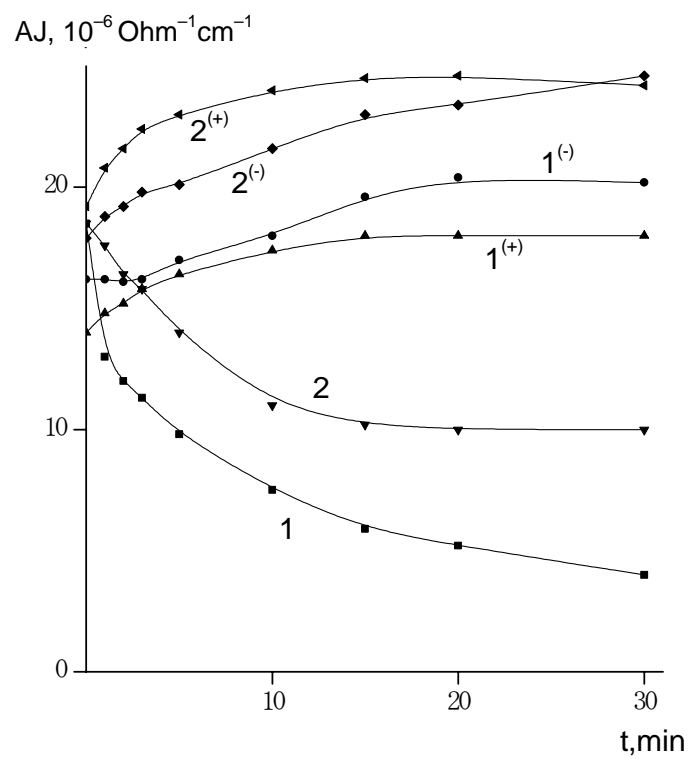

Fig. 5. $A J(t)$-dependences obtained for the electrode pair $\mathrm{Pt}-\mathrm{Si} \mathrm{p}^{\mathrm{p}}\left\langle\mathrm{Pd}, 10^{-3}\right\rangle\left(1,1^{(+)}, 1^{(-)}\right.$- before; $2,2^{(+)}, 2^{(-)}-$after thermal oxidation $\left.\mathrm{Si}^{\mathrm{p}}\right)$. $1,2-V_{0}=0 ;(+)-V_{0}=+9.7 \mathrm{~V},(-)-V_{0}=$ $=-9.7 \mathrm{~V}$ on $\mathrm{Si}^{\mathrm{p}}\left\langle\mathrm{Pd}, 10^{-3}\right\rangle$.

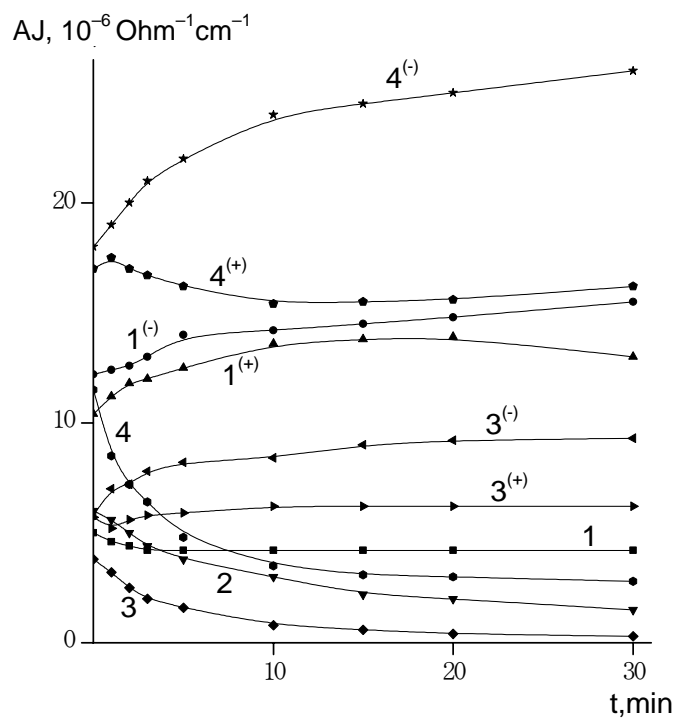

Fig. 6. $A J(t)$-dependences obtained for the electrode pair Pt$\mathrm{Si}^{\mathrm{t}}\left\langle\mathrm{Pd}, 10^{-2}\right\rangle \quad\left(1,1^{(+)}, 1^{(-)}\right), \quad \mathrm{Pt}^{-\mathrm{Si}^{\mathrm{t}}}\left\langle\mathrm{Pd}, 10^{-3}\right\rangle \quad(2)$ and $\mathrm{Al}-$ $\mathrm{Si}^{\mathrm{t}}\left\langle\mathrm{Pd}, 10^{-2}\right\rangle\left(3,3^{(+)}, 3^{(-)}\right), \mathrm{Al}-\mathrm{Si}^{\mathrm{t}}\left\langle\mathrm{Pd}, 10^{-3}\right\rangle\left(4,4^{(+)}, 4^{(-)}\right)$after thermal oxidation of $\mathrm{Si}^{\mathrm{t}}\langle\mathrm{Pd}\rangle .1,2,3,4-V_{0}=0 ; V_{0}=+9.7 \mathrm{~V}$ and $(-)-V_{0}=-9.7 \mathrm{~V}$ on $\mathrm{Si}^{\mathrm{t}}\langle\mathrm{Pd}\rangle$. The curves $2^{(+)}, 2^{(-)}$are not presented as they are very close to $1^{(+)}, 1^{(-)}$curves.

values, especially at $V_{\mathrm{o}}=0$ and $V_{0}=+9.7 \mathrm{~V}$ (Fig. 5, curves $2,2^{(+)}, 2^{(-)}$; Fig. 6 , curves $1,1^{(+)}, 1^{(-)}$and $2,2^{(+)}$).

$A J(t)$ dependences (Figs. 5 and 6) were obtained with Pt electrode when it always plays the role of cathode, while the doped silicon electrodes act as anodes. To ascertain the role of "cathode - anode", we obtained $A J(t)$ dependences for doped silicon structures (as cathodes) and $\mathrm{Al}$ electrode used as anode (Figs. 6 and 7). $A J(t)$ dependences inherent to doped textured electrodes with the $\mathrm{Al}$ counter-electrode after the thermal treatment (Fig. 6, curves $3,3^{(+)}, 3^{(-)}$and $4,4^{(+)}, 4^{(-)}$) have no principle differences as compared with those for the $\mathrm{Pt}$ counter-electrode, although $A J(t)$ magnitudes differ to some extent. It is seen from Fig. 6 that for the pair Al$\mathrm{Si}_{\mathrm{TT}}{ }_{\mathrm{t}}^{\mathrm{t}}\left\langle\mathrm{Pd}, 10^{-3}\right\rangle A J(t)$ values at $V_{0}=0, \pm 9.7 \mathrm{~V}$ are respectively higher (curves $4,4^{(+)}, 4^{(-)}$) than for the pair $\mathrm{Pt}_{-\mathrm{Si}_{\mathrm{TT}}}{ }^{\mathrm{t}}\left\langle\mathrm{Pd}, 10^{-3}\right\rangle$ (curves $2,2^{(+)}, 2^{(-)}$), while for the pair Al$\mathrm{Si}_{\mathrm{TT}}{ }^{\mathrm{t}}\left\langle\mathrm{Pd}, 10^{-2}\right\rangle$ (curves $\left.3,3^{(+)}, 3^{(-)}\right)$these are lower than for the pair $\mathrm{Pt}_{-} \mathrm{Si}_{\mathrm{TT}}{ }^{\mathrm{t}}\left\langle\mathrm{Pd}, 10^{-2}\right\rangle$ (curves $1,1^{(+)}, 1^{(-)}$). These data are indicative of the fact that the thermal treatment of silicon electrodes doped with various $\mathrm{Pd}$ concentrations results in their distinct properties.

If the thermal treatment of silicon electrodes doped with Pd enhances water decomposition when using the $\mathrm{Pt}$ counter-electrode, then when using $\mathrm{Al}$ and $\mathrm{Yb}$ counter-electrodes the rate of water decomposition $(A J(t)$ value) can both decrease and increase. The decrease can be clearly seen in Fig. 7 if comparing $A J(t)$ dependences for the pair $\mathrm{Al}-\mathrm{Si}^{\mathrm{p}}\left\langle\mathrm{Pd}, 10^{-3}\right\rangle$ at $V_{0}=0, \pm 9.7 \mathrm{~V}$ before (curves $3,3^{(+)}, 3^{(-)}$) and after (curves $4,4^{(+)}, 4^{(-)}$) the thermal treatment. Moreover, at $V_{0}=0$ even the character of $A J(t)$ dependences is distinct: before the thermal treatment it is ascending (curve 3 ) and after descending (curve 4). In its turn, it is caused by the growth or drop of $\Delta V_{c}$ with time of exposure, which can be related with different character of interaction between $\mathrm{H}^{+}$ions and surfaces of the $\mathrm{Si}\langle\mathrm{Pd}\rangle$ electrode before and after its thermal treatment.

When using the $\mathrm{Yb}$ electrode (Figs 7 and 8), at $V_{0}=0 A J(t)$ values are decreased after the thermal treatment (compare the curves 2 with curves 1 ). In the case of the $\mathrm{Si}^{\mathrm{t}}\left\langle\mathrm{Pd}, 10^{-2}\right\rangle$ electrode, lower $A J(t)$ values after the thermal treatment are also observed if applying to it (cathode) the voltage $V_{0}=-9.7 \mathrm{~V}$ (curve $2^{(-)}$as compared with the curve $1^{(-)}$, Fig. 8). However, for the electrode $\mathrm{Si}^{\mathrm{p}}\left\langle\mathrm{Pd}, 10^{-3}\right\rangle$ at $V_{0}= \pm 9.7 \mathrm{~V} A J(t)$ values grow after the treatment (curves $2^{(+)}, 2^{(-)}$as compared with the curves $1^{(+)}, 1^{(-)}$, Fig. 7). This diversity of results for $\mathrm{Si}^{\mathrm{t}}\langle\mathrm{Pd}\rangle$ and $\mathrm{Si}^{\mathrm{p}}\langle\mathrm{Pd}\rangle$ electrodes at $V_{0}=0$ and at $V_{0}=$ $\pm 9.7 \mathrm{~V}$ before and after the thermal treatment indicates that there changed are the mechanisms of $\mathrm{H}_{2} \mathrm{O}$ molecule decomposition as well as interaction of $\mathrm{H}^{+}$ions with $\mathrm{Si}\langle\mathrm{Pd}\rangle$ electrodes after changing the abovementioned factors. Fig. 8 illustrates also the dependence of $A J(t)$ values obtained after treating the $\mathrm{Si}^{\mathrm{t}}\langle\mathrm{Pd}\rangle$ on the concentration of $\mathrm{Pd}$ doping impurity (curves 2, $2^{(-)}$ $\left(10^{-2} \mathrm{M}\right)$ and curves $\left.3,3^{(+)}, 3^{(-)}\left(10^{-3} \mathrm{M}\right)\right)$.

Thus, silicon electrodes $\mathrm{Si}^{\mathrm{p}}$ and $\mathrm{Si}^{\mathrm{t}}$ coupled with $\mathrm{Pt}$ counter-electrodes enhance water decomposition (increase $A J(t)$ ) both after doping them with $\mathrm{Pd}$ and after following thermal oxidation. When using $\mathrm{Al}$ and $\mathrm{Yb}$ counter-electrodes, only in separate cases doping and the following thermal oxidation of $\mathrm{Si}^{\mathrm{p}}$ and $\mathrm{Si}^{\mathrm{t}}$ electrodes also increases $A J(t)$. The best result was obtained at $V_{0}=0$ using the $\mathrm{Si}^{\mathrm{p}}\left\langle\mathrm{Pd}, 10^{-3}\right\rangle$ electrode before its thermal oxidation $\left(A J_{\max }(t)=32 \cdot 10^{-6} \mathrm{Ohm}^{-1} \cdot \mathrm{cm}^{-1}\right)$. 


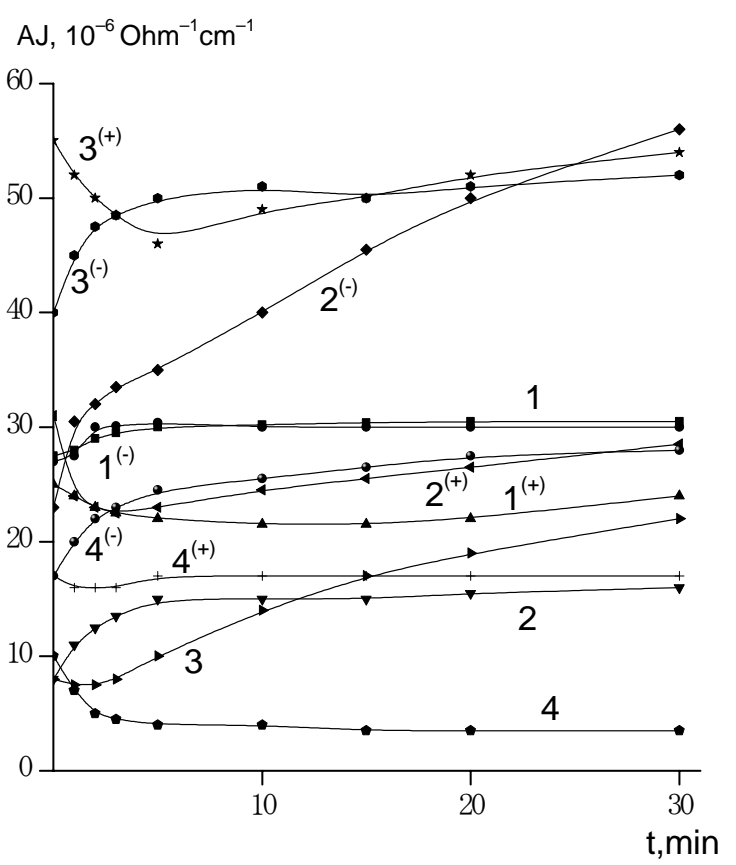

Fig. 7. $A J(t)$-dependences inherent to the electrode pairs $\mathrm{Yb}$ $\mathrm{Si}^{\mathrm{P}}\left\langle\mathrm{Pd}, 10^{-3}\right\rangle\left(1,1^{(+)}, 1^{(-)}-\right.$before; $2,2^{(+)}, 2^{(-)}-$after thermal oxidation of $\left.\mathrm{Si}^{\mathrm{p}}\left\langle\mathrm{Pd}, 10^{-3}\right\rangle\right)$ and $\mathrm{Al}-\mathrm{Si}^{\mathrm{p}}\left\langle\mathrm{Pd}, 10^{-3}\right\rangle\left(3,3^{(+)}, 3^{(-)}-\right.$ before; $4,4^{(+)}, 4^{(-)}-$after thermal oxidation of $\left.\mathrm{Si}^{\mathrm{p}}\left\langle\mathrm{Pd}, 10^{-3}\right\rangle\right) .1$, $2,3,4-V_{0}=0,(+)-V_{0}=+9.7 \mathrm{~V}$ and $(-)-V_{0}=-9.7 \mathrm{~V}$ on $\mathrm{Si}^{\mathrm{p}}\langle\mathrm{Pd}\rangle$.

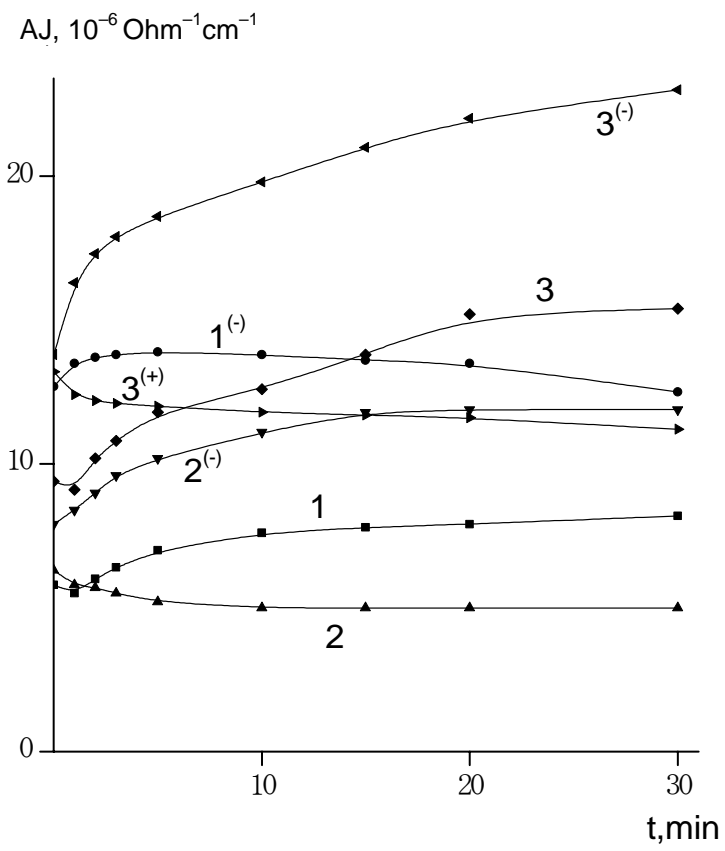

Fig, 8. $A J(t)$-dependences obtained for the electrode pairs $\mathrm{Yb}$ $\mathrm{Si}^{\mathrm{t}}\left\langle\mathrm{Pd}, 10^{-2}\right\rangle\left(1,1^{(-)}\right.$- before; $2,2^{(-)}-$after thermal oxidation of $\left.\mathrm{Si}^{\mathrm{t}}\left\langle\mathrm{Pd}, 10^{-2}\right\rangle\right)$ and $\mathrm{Yb}-\mathrm{Si}^{\mathrm{t}}\left\langle\mathrm{Pd}, 10^{-3}\right\rangle\left(3,3^{(+)}, 3^{(-)}-\right.$after thermal oxidation of $\left.\mathrm{Si}^{\mathrm{t}}\left\langle\mathrm{Pd}, 10^{-3}\right\rangle\right)$. 1, 2, $3-V_{0}=0,3^{(+)}-V_{0}=+9.7 \mathrm{~V}$; $1^{(-)}, 2^{(-)}, 3^{(-)}-V_{0}=-9.7 \mathrm{~V}$ on $\mathrm{Si}^{\mathrm{t}}\langle\mathrm{Pd}\rangle$.
At $V_{0}= \pm 9.7 \mathrm{~V}$, the best results $(A J(t)=$ $\left.(40 \ldots 55) \cdot 10^{-6} \mathrm{Ohm}^{-1} \cdot \mathrm{cm}^{-1}\right)$ were obtained using the thermally oxidized electrode $\mathrm{Si}_{\mathrm{TT}}^{\mathrm{p}}\left\langle\mathrm{Pd}, 10^{-3}\right\rangle$ coupled with the $\mathrm{Al}$ counter-electrode as well as using the same electrode at $V_{0}=-9.7 \mathrm{~V}$ on it in pair with $\mathrm{Yb}$ counterelectrode $\left(A J(t)=(25 \ldots 56) \cdot 10^{-6} \mathrm{Ohm}^{-1} \cdot \mathrm{cm}^{-1}\right)$.

III. To obtain high values of $A J(t)$ along with catalytic activity of electrodes as to water decomposition, it is necessary to have a higher difference $\Delta \varphi$ between electrodes, that is a minimal value of $\varphi$ on the anode and its maximal value on the cathode. Among catalytically active metals, the highest $\varphi$ values are inherent to $\mathrm{Pt}(5.32 \mathrm{eV})$ and $\mathrm{Pd}(5.00 \mathrm{eV})$ that are oxidized very weakly. As $\mathrm{Pt}$ and $\mathrm{Pd}$ are precious metals, it is reasonable to find cathodes from other materials with relatively high $\varphi$-values. In the work [2], we used the cathode from chromium silicide $\left(\mathrm{Cr}_{3} \mathrm{Si}\right)$. In this work, we investigated the influence of thermal oxidation of $\mathrm{Cr}_{3} \mathrm{Si}$ on $A J(t)$ dependences when using $\mathrm{Pt}$, $\mathrm{Yb}, \mathrm{Al}$ as counter-electrodes. We studied nickel silicide as well. The thermal treatment of $\mathrm{Cr}_{3} \mathrm{Si}$ and $\mathrm{Ni}_{3} \mathrm{Si}$ was performed in the same manner as for silicon electrodes at $850{ }^{\circ} \mathrm{C}$ in dry oxygen for one hour.

Measurements relatively to $\mathrm{Pt}$ electrode showed that before the thermal treatment $\varphi\left(\mathrm{Cr}_{3} \mathrm{Si}\right)=4.72 \mathrm{eV}$ and $\varphi\left(\mathrm{Ni}_{3} \mathrm{Si}\right)=4.85 \mathrm{eV}$, while after it $\varphi\left(\mathrm{Cr}_{3} \mathrm{Si}\right)_{\mathrm{TT}}=5.45 \mathrm{eV}$ and $\varphi\left(\mathrm{Ni}_{3} \mathrm{Si}\right)_{\mathrm{TT}}=4.89 \mathrm{eV}$. Thus, the thermal oxidation increased considerably the only $\varphi$-value for $\mathrm{Cr}_{3} \mathrm{Si}$. The same was also found when studying $A J(t)$ dependences with various counter-electrodes.

Shown in Fig. 9 are the $A J(t)$ dependences for the pair $\mathrm{Pt}-\mathrm{Cr}_{3} \mathrm{Si}$ before $\left(1,1^{(+)}, 1^{(-)}\right)$and after $\left(2,2^{(+)}, 2^{(-)}\right)$ thermal oxidation. The $A J(t)$-values obtained at $V_{0}=0$ (curves 1,2) indicate an alternating role of $\mathrm{Cr}_{3} \mathrm{Si}$ electrode coupled with the Pt one after the thermal treatment: instead of "anode" it becomes "cathode" (which is conventionally shown with the "sign" of the curve 2), conductivity of the system $\mathrm{Pt}-\mathrm{Cr}_{3} \mathrm{Si}$ being increased. The $A J(t)$-value is also essentially increased after the thermal treatment when applying the additional voltage $V_{0}= \pm 9.7 \mathrm{~V}$ to the $\mathrm{Cr}_{3} \mathrm{Si}$ electrode (curves $1^{(+)}$, $1^{(-)}$and $\left.2^{(+)}, 2^{(-)}\right)$.

Positive changes of the $A J(t)$ dependences after the thermal treatment of $\mathrm{Cr}_{3} \mathrm{Si}$ can be also observed in pairs $\mathrm{Al}-\mathrm{Cr}_{3} \mathrm{Si}$ (Fig. 10) and $\mathrm{Yb}_{-} \mathrm{Cr}_{3} \mathrm{Si}$ (Fig. 11). If the $\mathrm{Yb}$ electrode is used, thermal oxidation of $\mathrm{Cr}_{3} \mathrm{Si}$ improves all the $A J(t)$ dependences (at $V_{0}=0$ and $V_{0}= \pm 9.7 \mathrm{~V}$ ). Rather high $A J(t)$ values in the case of the thermally oxidized $\mathrm{Cr}_{3} \mathrm{Si}$ allows to hope that there is a principle opportunity to solve the problem of the efficient electrode based on silicides and their oxides. For the pair $\mathrm{Al}-\mathrm{Cr}_{3} \mathrm{Si}$, thermal oxidation improves $A J(t)$ dependences at $V_{0}= \pm 9.7 \mathrm{~V}$. The $A J(t)$ dependences at $V_{0}=0$ also have a tendency to improve after thermal oxidation at $t \geq 28$ min exposures (curves 1,2). In addition, Fig. 10 contains the $A J(t)$ dependence for the $\mathrm{Cr}_{3} \mathrm{Si}$ electrode grinded with abrasive (grain diameter is close to $10 \mu \mathrm{m}$ ) before oxidation (curve $1^{\mathrm{p}}$ ). It is seen that grinding 
(texturing) the electrode results in its enhanced catalytical activity when decomposing water before making the circuit to close.

Nickel silicide $\mathrm{Ni}_{3} \mathrm{Si}$ was found to be less efficient cathode even after its thermal oxidation. The $A J(t)$ values both before and after the thermal oxidation of $\mathrm{Ni}_{3} \mathrm{Si}$ coupled with other electrodes were, as a rule, less at $V_{0}=0$ and $V_{0}= \pm 9.7 \mathrm{~V}$ than the respective $A J(t)$-values for the $\mathrm{Cr}_{3} \mathrm{Si}$ electrode. Possibly, it is caused by some

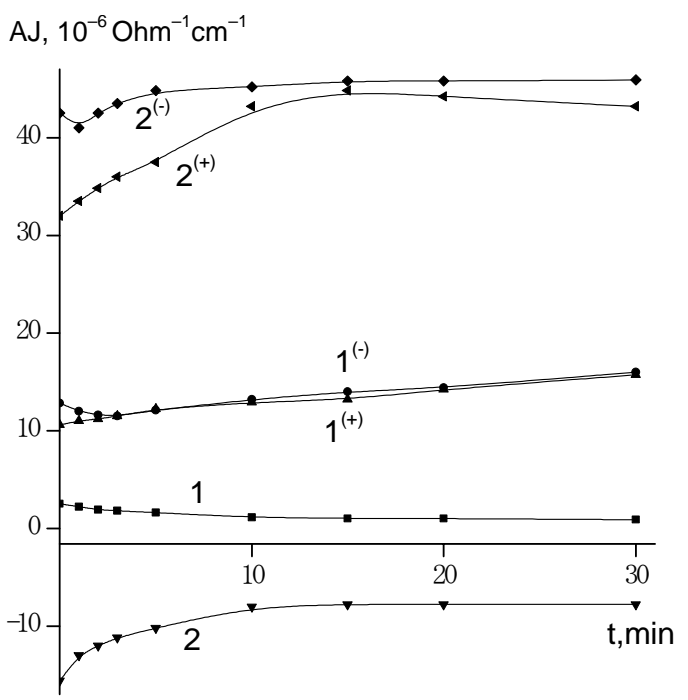

Fig. 9. $A J(t)$-dependences measured using the electrode pair $\mathrm{Pt}_{-} \mathrm{Cr}_{3} \mathrm{Si}\left(1,1^{(+)}, 1^{(-)}\right.$-before thermal oxidation; $2,2^{(+)}, 2^{(-)}$ after thermal oxidation $\left.\mathrm{Cr}_{3} \mathrm{Si}\right) .1,2-V_{0}=0,(+)-V_{0}=$ $=+9.7 \mathrm{~V},(-)-V_{0}=-9.7 \mathrm{~V}$ on $\mathrm{Cr}_{3} \mathrm{Si}$.

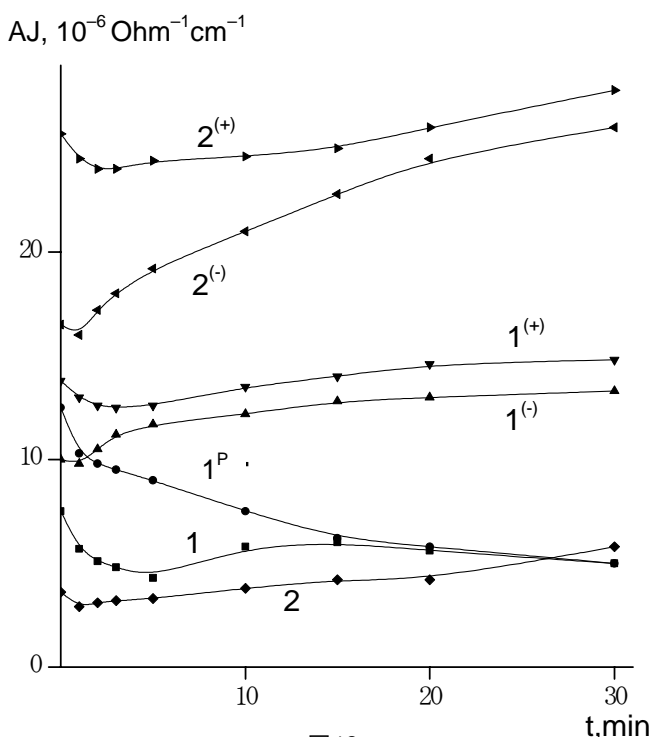

Fig. 10. $A J(t)$-dependences measured using the electrode pair $\mathrm{Al}-\mathrm{Cr}_{3} \mathrm{Si}\left(1,1^{(+)}, 1^{(-)}, 1^{\mathrm{p}}\right.$ - before thermal oxidation, 2, $2^{(+)}, 2^{(-)}-$after thermal oxidation of $\left.\mathrm{Cr}_{3} \mathrm{Si}\right) .1,1^{\mathrm{p}}, 2-V_{0}=0$; $(+)-V_{0}=+9.7 \mathrm{~V},(-)-V_{0}=-9.7 \mathrm{~V}$ on $\mathrm{Cr}_{3} \mathrm{Si}$. distinctions in $\mathrm{Ni}_{3} \mathrm{Si}$ production technology, which results in less porous structure of $\mathrm{Ni}_{3} \mathrm{Si}$ than that of $\mathrm{Cr}_{3} \mathrm{Si}$. Our work aimed at production of more efficient cathodes based on silicides via changing their composition and structure is going on.

The investigations performed in this work are a definite stage on the way to obtain a source of current and hydrogen by using the water decomposition based on a natural difference of electrochemical potentials inherent to various materials both existing in nature and that produced artificially without great energy and material expenses. To solve this problem, we plan, first of all, to obtain positive solutions of the following tasks: i) choice of catalytically active electrodes (both cathode and anode) capable to decompose water and made of various materials, studying the structural and chemical states of their surface, which could provide a higher potential difference between the electrodes without losses of their catalytic activity; ii) stability and selfreproducibility of electrodes in the course of operation; iii) technical solution for creation of an efficient electrochemical system capable to yield the energy from water by using the electric current and hydrogen, etc.

It is noteworthy that this work is promising in creation of a photoelectrochemical system that could use not only the abovementioned processes to yield the energy but conversion the solar energy, too. Really, the oxide film $\mathrm{SiO}_{2}$ obtained on a silicon surface and possessing a wide forbidden gap can be doped with impurities (using, for example, the method of ion implantation) that could absorb solar quanta and due to two(or three)-photon electron transitions provide current creation in the electrochemical system.

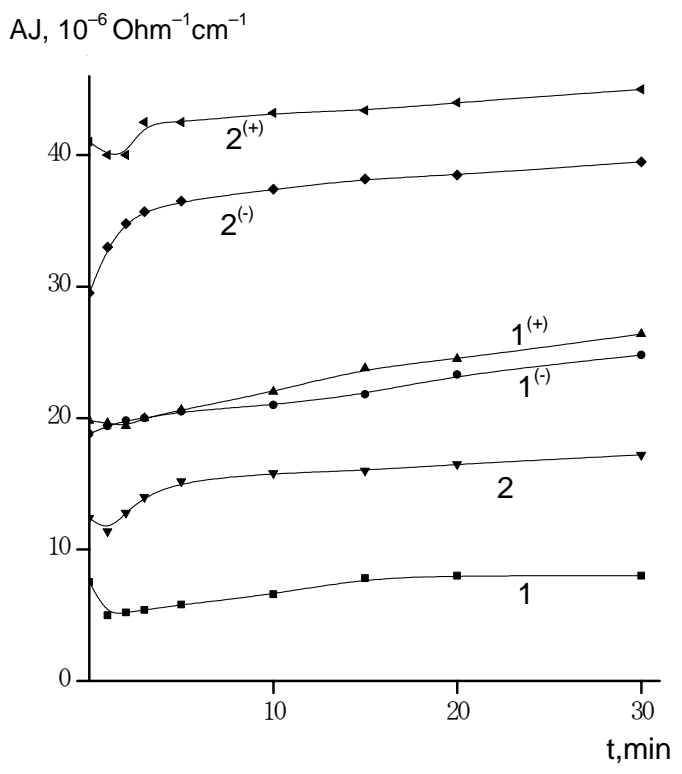

Fig. 11. $A J(t)$-dependences measured using the electrode pair Yb-Cr 3 Si $\left(1,1^{(+)}, 1^{(-)}\right.$- before; $2,2^{(+)}, 2^{(-)}-$after thermal oxidation of $\left.\mathrm{Cr}_{3} \mathrm{Si}\right) .1,2-V_{0}=0 ;(+)-V_{0}=+9.7 \mathrm{~V},(-)-V_{0}=$ $=-9.7 \mathrm{~V}$ on $\mathrm{Cr}_{3} \mathrm{Si}$ ). 


\section{Conclusions}

1. Investigated were the time dependences of the effective conductivity $A J(t)$ for electrochemical systems capable to decompose water due to catalytic processes on the electrodes and a potential difference between them. We used electrodes based on modified silicon (polished, chemically textured, doped with palladium silicon surface, silicides of metals) and counterelectrodes from $\mathrm{Al}, \mathrm{Pt}, \mathrm{Yb}$ both in absence of external voltage in the electric circuit $\left(V_{0}=0\right)$ and in presence of it $\left(V_{0}= \pm 9.7 \mathrm{~V}\right)$ on the silicon electrode. It was found that the most efficient water decomposition takes place on the polished and then doped with Pd silicon surface.

2. Investigated was the influence of thermal oxidation of silicon electrodes $\left(850^{\circ} \mathrm{C}\right.$, dry $\mathrm{O}_{2}, 1$ hour $)$ on $A J(t)$ dependences when using $\mathrm{Al}, \mathrm{Pt}, \mathrm{Yb}$ as counterelectrodes. Found were both positive and negative role of thermal oxidation, an essential role of Pd doping before thermal oxidation, the opportunity to use thermal oxidation for changing the electron work function $\varphi$ for silicon electrodes in a rather wide interval $(\varphi \approx$ $\approx 4.5 \ldots 11.5 \mathrm{eV}$ ). Thermal oxidation of $\mathrm{Cr}_{3} \mathrm{Si}$ was also efficient for enhancing water decomposition.

\section{Acknowledgments}

Authors express their sincere gratitude to I.V. Kud' for growing chromium and nickel silicides.

\section{References}

1. V.E. Primachenko, B.M. Bulach, S.I. Kirillova, V.A. Chernobay, E.F. Venger, Electronic properties of palladium-doped porous silicon and its application for water decomposition without applying electric voltage // Ukr. J. Phys. 52(3), p. 236-243 (2007).

2. V.E. Primachenko, I.V. Kud', V.A. Chernobay, Decomposition of water under application of electrodes with catalytic properties // Zhurnal tekhnicheskoy fiziki (to be published).

3. Short chemical encyclopedia. Sov. Encyclopedia, Moscow, 1963 (in Russian).

4. S.I. Kirillova, V.E. Primachenko, A.A. Serba, L.P. Tarasenko, V.A. Chernobay, Temperature dependence of surface potential on textural silicon surface. // Optoelektronika i poluprovodnikovaya tekhnika, N 27, p. 29-35 (1994) (in Russian).

5. F.S. Fomenko, Emission properties of materials. Naukova dumka, Kiev, 1981 (in Russian).

6. Fizicheskaya encyclopedia. Sov. Encyclopedia, Moscow, 1988 (in Russian).

7. V.A. Mjamlin, Ju.V. Pleskov, Electrochemistry of semiconductors. Nauka, Moscow, 1965 (in Russian).

8. V.E. Primachenko, O.V. Snitko, Physics of metal doped semiconductors surfaces. Naukova dumka, Kiev, 1988 (in Russian).

9. L.I. Antropov, Theoretical electrochemistry. Vysshaja shkola, Moscow, 1984 (in Russian).

10. S.M. Sze, Physics of semiconductor devices. John Wiley and Sons, Toronto-Singapure, 1981. 